\title{
Methotrexate-associated Classical Hodgkin Lymphoma Shows Distinct Clinicopathological Features but Comparable Clinical Outcomes With Sporadic Cases
}

\author{
KOTA YOSHIFUJI, YOSHIHIRO UMEZAWA, AYAKO ICHIKAWA, \\ KEN WATANABE, OSAMU MIURA and MASAHIDE YAMAMOTO \\ Department of Hematology, Tokyo Medical and Dental University, Tokyo, Japan
}

\begin{abstract}
Background/Aim: Methotrexate (MTX)-associated classical Hodgkin lymphoma $(\mathrm{CHL})$ is a rare disease, and its prognosis remains unclear. Materials and Methods: Our study retrospectively compared clinicopathological features and clinical outcomes of patients with MTX-CHL $(n=6)$ and sporadic CHL $(n=40)$. Results: MTX-CHL was more frequently the mixed cellularity subtype and positive for Epstein-Barr virus, but less frequently positive for CD20 than sporadic CHL. Clinically, MTX-CHL was more frequent in advanced stage than sporadic CHL and often associated with extranodal disease. After the cessation of MTX, transient spontaneous regression was observed in two MTX-CHL cases. Eventually, all patients with MTX-CHL required chemotherapy, which gave similar complete remission rates at 2 years compared to sporadic CHL. Patients with MTX-CHL tended to have a higher incidence of grade 3 or more neutropenia. Conclusion: The present study revealed differences in clinicopathological features but similarities in clinical outcomes of MTX-CHL and sporadic CHL.
\end{abstract}

Other iatrogenic immunodeficiency-associated lymphoproliferative disorders (LPDs) typically develop in patients with autoimmune diseases who are receiving methotrexate (MTX) and other biological immunosuppressive drugs (1). MTX was the first anticancer/immunosuppressive drug to be associated with LPDs $(2,3)$. LPDs in patients treated with MTX are defined as MTX-associated LPDs (MTX-LPDs).

This article is freely accessible online.

Correspondence to: Masahide Yamamoto, Department of Hematology, Tokyo Medical and Dental University, 1-5-45 Yushima, Bunkyo-ku, Tokyo 113-8519, Japan. Tel: +81 358035211, Fax: +81 358030110, e-mail: hide.hema@tmd.ac.jp

Key Words: Methotrexate, methotrexate-associated lymphoproliferative disorders, methotrexate-associated classical Hodgkin lymphoma, spontaneous remission, absolute lymphocyte count.
MTX-LPDs exhibit various histopathological features. The most common subtype is diffuse large B-cell lymphoma (DLBCL), while classical Hodgkin's lymphoma (CHL) type accounts for $12-25 \%$ of all MTX-LPDs (1). It has been reported that approximately $80 \%$ of patients with MTXDLBCL exhibit remission after MTX discontinuation alone and need no additional chemotherapy (4). Furthermore, other studies have found that patients with MTX-DLBCL who need additional chemotherapy because of disease progression have a better prognosis than those with sporadic DLBCL after receiving rituximab-containing chemotherapy $(5,6)$.

In contrast, the majority of patients with MTX-CHL require additional chemotherapy $(1,4,7,8)$; their prognosis remains unclear because of the rarity of MTX-CHL. To order to elucidate the differences between MTX-CHL and sporadic CHL, we retrospectively analyzed and compared the clinicopathological features and clinical outcomes of such cases at our Institution.

\section{Materials and Methods}

Patients. This study retrospectively analyzed patients with newly diagnosed CHL who were treated at the Tokyo Medical and Dental University Hospital between March 1995 and June 2016. Institutional Review Board approval was obtained (M2017-086). All patients were diagnosed via biopsy of the primary lesion. No patient had previously received chemotherapy for other malignancies. Cases pathologically diagnosed as CHL during continued MTX therapy were defined as MTX-CHL. The staging and response were defined following the Lugano Criteria (9).

Statistical analysis. Clinicopathological differences between patients with sporadic CHL and those with MTX-CHL were compared using Student's $t$ - and chi-square tests. Overall survival (OS) was defined as the time from the date of starting chemotherapy to the date of death from any cause or censored at the date of last contact. Progression-free survival (PFS) was defined as the time from the date of starting chemotherapy to date of relapse or death. The Kaplan-Meier method was used to estimate OS and PFS. Differences in survival between the two groups were analyzed by 
in vivo 33: 1599-1604 (2019)

Table I. Clinical background and treatment of methotrexate (MTX)-associated classical Hodgkin lymphoma.

\begin{tabular}{|c|c|c|c|c|c|c|}
\hline & Case 1 & Case 2 & Case 3 & Case 4 & Case 5 & Case 6 \\
\hline Age, years & 71 & 55 & 48 & 72 & 58 & 57 \\
\hline Gender & Female & Female & Male & Female & Female & Male \\
\hline Pathology & $\mathrm{MC}$ & MC & $\mathrm{MC}$ & MC & $\mathrm{MC}$ & ND \\
\hline Primary disease & RA & RA & RA & $\mathrm{RA} / \mathrm{SS}$ & RA & PA \\
\hline Duration of MTX (years) & 6 & 13 & 6 & 6 & 6 & 5 \\
\hline $\begin{array}{l}\text { Other immunotherapies } \\
\text { PSL, IFX }\end{array}$ & BUC, ETN, & SASP & $\begin{array}{l}\text { PSL, BUC, } \\
\text { PSL, IFX }\end{array}$ & $\begin{array}{c}\text { BUC, SASP, } \\
\text { IFX, ADA }\end{array}$ & BUC, PSL, & IFX \\
\hline \multicolumn{7}{|l|}{ Involved site } \\
\hline $\begin{array}{l}\text { Lymph node } \\
\text { Extranodal site }\end{array}$ & $\begin{array}{c}\mathrm{C}, \mathrm{A}, \mathrm{M}, \mathrm{H}, \mathrm{P}^{*}, \mathrm{I} \\
\text { Bone }\end{array}$ & $\mathrm{C}^{*}, \mathrm{M}, \mathrm{H}, \mathrm{P}$ & $\begin{array}{l}\mathrm{C}^{*}, \mathrm{~A}, \mathrm{M}, \mathrm{H}, \mathrm{P} \\
\text { Lung }\end{array}$ & $\begin{array}{c}\mathrm{C}, \mathrm{M}, \mathrm{H}, \mathrm{P}^{*}, \text { Spleen } \\
\text { Bone }\end{array}$ & $\mathrm{C}^{*}, \mathrm{M}, \mathrm{S}$ & $\mathrm{W}^{*}, \mathrm{C}, \mathrm{P}$ \\
\hline \multicolumn{7}{|l|}{$\begin{array}{l}\mathrm{WBC}(\mathrm{n} / \mu \mathrm{l}) / \mathrm{ALC} \\
(\mathrm{n} / \mu \mathrm{l}) / \mathrm{CRP}(\mathrm{mg} / \mathrm{dl})\end{array}$} \\
\hline At diagnosis & $3200 / 460 / 10.81$ & $3700 / 359 / 5.4$ & $13900 / 902 / 8.24$ & $2400 / 902 / 0.05$ & $6200 / 1910 / 0.47$ & $7000 / 1400 / 0.15$ \\
\hline 2 Weeks after MTX cessation & $3800 / 1322 / 0.36$ & $7200 / 1872 / 0.32$ & $11300 / 1356 / 4.2$ & $2900 / 1131 / 0.13$ & $4900 / 1078 / 1.67$ & $7700 / 2618 / 0.06$ \\
\hline Regrowth & $5900 / 236 / 8.29$ & $8100 / 810 / 6.58$ & - & - & - & - \\
\hline EBER & + & + & + & + & + & - \\
\hline \multicolumn{7}{|l|}{ Response } \\
\hline After MTX withdrawal & $\begin{array}{l}\text { Regression -> } \\
\text { regrowth } \\
(13 \text { months })\end{array}$ & $\begin{array}{c}\text { Regression -> } \\
\text { regrowth } \\
(30 \text { months })\end{array}$ & No change & No change & No change & No change \\
\hline After ABVD chemotherapy & CR & $\mathrm{CR}$ & $\mathrm{CR}$ & $\mathrm{CR}$ & $\mathrm{CR}$ & SD \\
\hline
\end{tabular}

MC: Mixed cellularity, ND: not determined; ALC: absolute lymphocyte count; RA: rheumatoid arthritis; SS: Sjogren syndrome; PA: psoriatic arthritis; BUC: bucilamin; ETN: etanercept; PSL: prednisolone; C: cervical; A: axillary; M: mediastinal; H: hilar; P: para-aortic; I: Iliac; S: spleen; W: Waldeyer's ring; EBER: Epstein-Bar virus-encoded small RNA: IFX: infliximab, SASP: salazosulfapyridine, ADA: adalimumab, ABVD: doxorubicin, bleomycin, vincristine and procarbazine *Biopsy site.

the log-rank test. All reported $p$-values were two-sided, and values of $p<0.05$ were considered significant. All analyses were carried out with EZR software (Saitama Medical Center, Jichi Medical University, Saitama, Japan), which is a graphical user interface for R (The R Foundation for Statistical computing) (10).

\section{Results}

Clinical background and treatment of MTX-CHL. Forty-six patients were diagnosed with CHL during the study period, with six defined as having MTX-CHL. The clinical features of MTX-CHL are shown in Table I. The median age at diagnosis was 58 years (range $=48-72$ years). There were four females and two males. The indications for MTX treatment were rheumatoid arthritis (RA) in four, RA with Sjogren syndrome in one, and psoriatic arthritis in one. The median duration of MTX treatment was 6 years (range=5-13 years). Four patients also received biological immunomodulatory agents. All patients had bilateral diaphragmatic involvement, and three out of the six had extranodal lesions in the bone or lungs. MTX was discontinued immediately after MTX-CHL was diagnosed. After cessation, four patients showed no regression and two showed only transient regression. In the two patients who showed transient regression, the absolute lymphocyte count (ALC) was lower than 500/ $\mu$ l at the time of MTX-CHL diagnosis, which then increased after MTX cessation. However, ALC decreased again with the relapse of CHL. Conversely, the C-reactive protein (CRP) level was elevated at the time of diagnosis, decreased after MTX cessation, and increased again at relapse.

All patients except one were positive for Epstein-Barr virus-encoded small RNA (EBER), and all received induction therapy with doxorubicin, bleomycin, vincristine, and dacarbazine (ABVD) at a median of 2.5 months after MTX cessation. Five out of the six patients achieved complete remission (CR). The remaining patient whose treatment response was stable disease after two cycles of ABVD was converted to escalated therapy with bleomycin, etoposide, doxorubicin, cyclophosphamide, vincristine, procarbazine, and prednisone [dose-escalated bleomycin, etoposide, doxorubicin, cyclophosphamide, vincristine, procarbazine, and prednisone (BEACOPP)]; CR was achieved after four cycles.

Comparison of the clinicopathological features between patients with MTX-CHL and sporadic CHL. Patient characteristics of both groups are shown in Table II. Median age was 58 years for the MTX-CHL group $(n=6)$ and 45 years in the sporadic CHL group $(n=40)$. Histopathologically, the percentage of patients with mixed cellularity subtype CHL was significantly higher in the MTX-CHL group than 
Table II. Differences of clinicopathological characteristics between patients with methotrexate (MTX)-associated classical Hodgkin lymphoma (CHL) and sporadic CHL.

\begin{tabular}{|c|c|c|c|}
\hline & MTX-CHL (n=6) & Sporadic CHL $(n=40)$ & $p$-Value \\
\hline Age (median) & $58(48-72)$ & $45(17-83)$ & 0.119 \\
\hline Gender n (\%) & & & 0.504 \\
\hline Male & $2(33 \%)$ & $23(58 \%)$ & \\
\hline Female & $4(66 \%)$ & $17(43 \%)$ & \\
\hline \multicolumn{4}{|l|}{ Pathology n (\%) } \\
\hline Nodular sclerosis & 0 & $16 / 38(42 \%)$ & \\
\hline Mixed cellularity & $5 / 5(100 \%)$ & $16 / 38(42 \%)$ & 0.040 \\
\hline Other & & $6 / 38(16 \%)$ & \\
\hline CD30 positive $\mathrm{n}(\%)$ & $6 / 6(100 \%)$ & $26 / 26(100 \%)$ & \\
\hline CD20 positive n (\%) & $0 / 6(0 \%)$ & $10 / 26(38 \%)$ & 0.023 \\
\hline EBER positive n (\%) & $5 / 6(83 \%)$ & $9 / 20(45 \%)$ & 0.008 \\
\hline Ann Arbor stage (stage IIII-IV) & $6(100 \%)$ & $19(48 \%)$ & 0.049 \\
\hline B Symptoms & $2(33 \%)$ & $11(28 \%)$ & 1 \\
\hline Bulky mass & $0(0 \%)$ & $7(18 \%)$ & 0.615 \\
\hline Extranodal site & $3(50 \%)$ & $11(28 \%)$ & 0.521 \\
\hline Bone marrow & 0 & 3 & \\
\hline Lung & 1 & 4 & \\
\hline Bone & 2 & 4 & \\
\hline Other & & Heart: 1 , liver: 1 , nasal: 1 & \\
\hline Median WBC (n/ $\mu \mathrm{l})$ & $4950(2400-13900)$ & $7150(2300-24300)$ & 0.174 \\
\hline Median ALC (n/ $/ \mu \mathrm{l})$ & $1151(359-1910)$ & $1200(174-3040)$ & 0.479 \\
\hline Median LDH (U/l) & $249(180-350)$ & $235(150-750)$ & 0.707 \\
\hline Median CRP (mg/dl) & $2.94(0-05-10.81)$ & $2.4(0-18.47)$ & 0.739 \\
\hline Median sIL2R (U/ml) & $1735(812-3500)$ & $1350(267-10200)$ & 0.754 \\
\hline GHSG (early-stage) Favorable/unfavorable, n & - & $12 / 9$ & \\
\hline IPS (advanced-stage) good/poor, n & $5 / 1$ & $12 / 7$ & 0.673 \\
\hline $\mathrm{CR}$ after induction therapy, $\mathrm{n}(\%)$ & $5 / 6(83 \%)$ & $35 / 38(92 \%)$ & $>0.99$ \\
\hline
\end{tabular}

EBER: Epstein-Bar virus-encoded small RNA; WBC: white blood count; ALC: absolute lymphocyte count; sIL2R: soluble interleukin-2 receptor LDH: lactate dehydrogenase; CRP: C-reactive protein; GHSG: German Hodgkin Study Group; IPS: International Prognostic Score; CR: complete remission.

the sporadic CHL group (100\% vs. $42 \%, p=0.04)$. The EBER-positive rate was also significantly higher in the MTX-CHL group than the sporadic CHL group ( $83 \%$ vs. $45 \%, p=0.008)$, while the rate of positive immunohistochemical staining for CD20 was significantly lower in the MTX-CHL group than the sporadic CHL group $(0 \% v s .38 \%, p=0.023)$. A significantly higher proportion of patients with MTX-CHL had advanced-stage CHL compared to those with sporadic CHL (100\% vs. $48 \%, p=0.049)$. Furthermore, the proportion of patients with extranodal diseases was higher in the MTX-CHL group than the sporadic CHL group (50\% vs. $28 \%, p=0.521$ ), although the difference was not statistically significant.

The CR rates after induction therapy were not different between the MTX-CHL and sporadic CHL groups (83\% vs. $92 \%, p>0.99$ ). Four patients whose responses were less than partial remission received salvage therapy (three chemotherapy, one radiotherapy), and three out of these four responded (two CRs, one partial), including one patient with MTX-CHL.
Adverse events, postponement, and dose reduction of $A B V D$. Adverse events (AE) of induction therapy are shown in Table III. The incidence of grade 3 neutropenia tended to be higher in the MTX-CHL group than the group with sporadic CHL ( $100 \%$ vs. $57 \%, p=0.13)$. There were no differences between the two groups in non-hematological AEs. We also evaluated postponement and dose reduction of ABVD therapy. The median cycle duration tended to be longer in the MTX-CHL group than the sporadic CHL group (35 vs. 28 days, respectively, $p=0.44$ ), and dose reductions were more common in the MTX-CHL group than the sporadic CHL group ( $80 \%$ vs. $29 \%$, respectively, $p=0.05)$.

Survival. The median follow-up was 48 months (range $=8-66$ months) in the MTX-CHL group and 64 months (range=1258 months) in the sporadic CHL group. PFS and OS are shown in Figure 1. There were no significant differences between the MTX-CHL and sporadic CHL groups in 2-year PFS $(83.3 \% v s .72 .8 \%, p=0.81)$ or 2 -year OS $(100 \% v s$. $94.3 \%, p=0.43)$. 

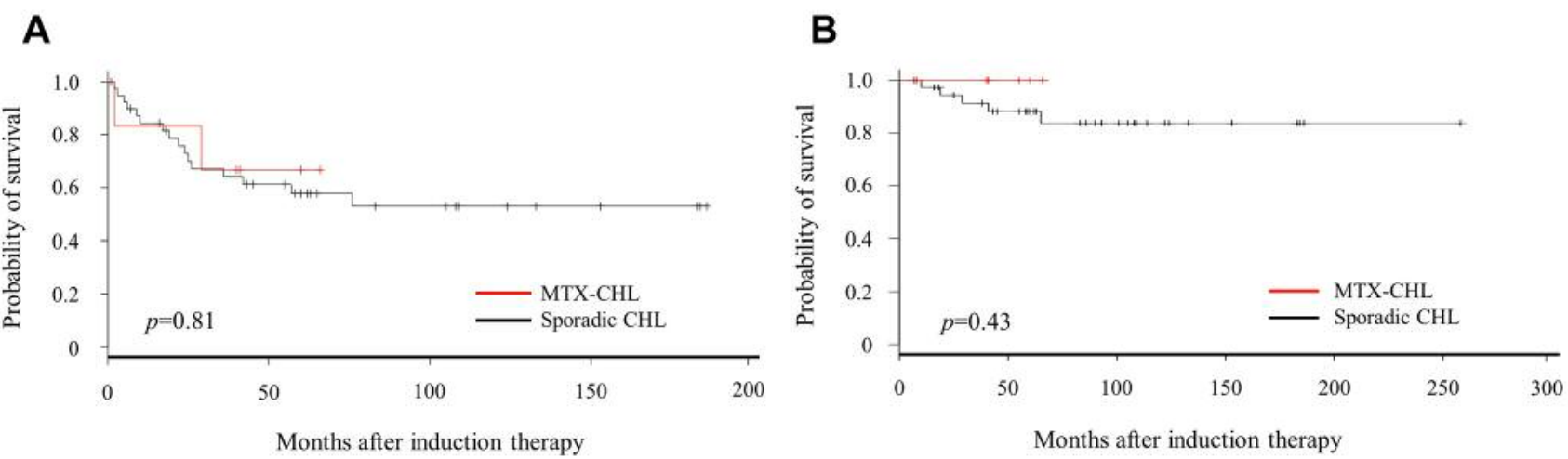

Figure 1. Progression-free $(A)$ and overall $(B)$ survival of patients with methotrexate (MTX)-associated classical Hodgkin lymphoma (CHL) and sporadic CHL.

Table III. Adverse events, cycle duration and dose reduction of doxorubicin, bleomycin, vincristine, and dacarbazine in patients with methotrexate (MTX)-associated classical Hodgkin lymphoma (CHL) and sporadic CHL.

\begin{tabular}{lccc}
\hline & MTX-CHL $(\mathrm{n}=5)$ & Sporadic CHL $(\mathrm{n}=21)$ & $p$-Value \\
\hline Adverse events & & & 0.129 \\
$\quad$ Neutropenia, grade $\geq 3$ & $5(100 \%)$ & $12(57 \%)$ & 0 \\
Thrombocytopenia, grade $\geq 3$ & 0 & $1(5 \%)$ & 0.488 \\
Liver dysfunction, grade $\geq 2$ & $1(20 \%)$ & 0 & 0.442 \\
Renal dysfunction, grade $\geq 2$ & 0 & $28(28-42)$ & 0.055 \\
Median cycle duration (range), days & $35(28-42)$ & $6(29 \%)$ & \\
Dose reduction, $n(\%)$ & $4(80 \%)$ & & \\
\hline
\end{tabular}

\section{Discussion}

The present study revealed that a significantly higher proportion of cases of MTX-CHL were of the mixed cellularity subtype and EBER-positive compared to sporadic $\mathrm{CHL}$, while the rate of $\mathrm{CD} 20$-positive cases in MTX-CHL was significantly lower. Although there have been few studies reporting the subtypes of MTX-CHL, Loo et al. reported that $61 \%$ of CHLs arising in patients with autoimmune diseases were the mixed cellularity subtype (7). In the present study, this subtype accounted for all the MTX-CHL cases in which the subtype could be determined $(5 / 5)$, while $42 \%$ of sporadic cases showed this subtype in accordance with the generally reported rate of $20-25 \%$ (1). Thus, we consider that the mixed cellularity subtype is a typical although not defining characteristic of MTX-CHL. In this study, the proportion of EBER-positive cases of MTX-CHL was also high $(83 \%)$, in agreement with previous reports $(4,7)$, and was significantly higher than that of sporadic CHL $(45 \%)$. This high positive rate may be partly explained by the fact that $75 \%$ of mixed cellularity subtype CHLs have been reported to be EBER- positive (1); all the MTX-CHL cases in this study were mixed cellularity subtype. On the other hand, none of our MTX-CHL cases were positive for CD20, which is consistent with a previous study that reported only one CD20-positive case among 17 MTX-CHL cases (4). In contrast, $38 \%$ of our sporadic CHL cases were positive for CD20, which is comparable to previous reports (18-40\%) $(1,11,12)$. We found the difference between the groups to be statistically significant.

Although it is well established that more than $60 \%$ of patients with sporadic CHL have localized disease (1), all patients with MTX-CHL had advanced-stage CHL at the time of diagnosis in our study. Moreover, although extranodal disease is reported to be generally rare in sporadic CHL $(1,13)$, we identified it in $28 \%$ of our sporadic CHL cases. Fifty percent of patients with MTX-CHL had extranodal disease in our study, which is in agreement with previous studies that reported high rates of advanced-stage CHL and extranodal disease in $40-70 \%$ of patients with MTX-CHL (4, 7, 14). Therefore, high rates of advancedstage CHL and extranodal disease are also typical clinical characteristics of MTX-CHL. 
After the cessation of MTX, two out of six patients showed disease regression. The ALCs of both patients were lower than $500 / \mu l$ at the time of diagnosis and increased rapidly 2 weeks after MTX was discontinued. A similar relationship between ALC recovery and disease regression has been reported $(15,16)$. MTX withdrawal resulted in immunological recovery and CR in $25-69 \%$ of patients with MTX-DLBCL $(4,14,17)$. In contrast, almost all patients with MTX-CHL do not achieve remission nor immunological recovery $(1,4,7,8)$. In accordance with this, two patients in our study experienced a transient regression after ALC recovery, but both patients then experienced relapse. Disease relapse after transient regression has been reported in MTX-CHL (4, 14, 17), but the relationship between ALC and relapse has not been well-explained. Considering that the ALC decreased and the CRP level increased when the disease relapsed in both our patients, both might reflect disease activity and could possibly become promising markers for MTX-CHL in this regard.

All patients with MTX-CHL in this study eventually received ABVD chemotherapy because of residual disease or progression, with a response rate comparable to that of sporadic CHL. Previous studies have also reported that most MTX-CHL cases need chemotherapy and have a good response $(4,7,8,14)$. Concerning the AEs of ABVD, the incidence of grade 3 or more neutropenia tended to be higher and more patients required postponement or dose reduction in the MTX-CHL group, although these were not significantly different from those of the sporadic CHL group, most likely due to small sample size. The PFS and OS after initial treatment showed no difference between the two groups.

Although this study examined only six MTX-CHL patients, this is the first report that compared MTX-CHL with sporadic CHL with respect to clinicopathological features and treatment outcomes. Certain pathological features (mixed cellularity subtype, EBER positivity, CD20 negativity) and clinical features (advanced stage, extranodal disease) were proposed as important features of MTX-CHL. Moreover, recovery of ALC after MTX cessation correlated with and was implicated in transient regression of lymphoma. The present study further revealed that MTXCHL did not differ from sporadic CHL in response to chemotherapy, PFS, or OS.

One unanswered question that remains regarding MTXCHL is when to start chemotherapy. Our study demonstrated that patients with MTX-CHL eventually needed chemotherapy and suggested that timing of chemotherapy might not have affected the outcome. Considering the aggravation of autoimmune disease symptoms after the cessation of MTX, early intervention after diagnosis may be preferable in order to manage both the autoimmune disease and MTX-CHL. Another remaining question is the optimum chemotherapy regimen for these patients. A meta-analysis has shown the superior efficacy of BEACOPP over ABVD in the treatment of CHL (18). Moreover, brentuximab vedotin, doxorubicin and vincristine with dacarbazine (AAVD) has recently been reported to show a better therapeutic effect than ABVD in advanced-stage CHL (19). The effectiveness of brentuximab vedotin for relapsed MTX-CHL has also been reported (20). Because the great majority of patients with MTX-CHL have advanced-stage disease, A-AVD may be more effective than ABVD for these patients. However, our study showed that patients with MTX-CHL showed more severe myelosuppression than two sporadic CHL. Myelosuppression is also reportedly more severe after A-AVD than ABVD (19). Therefore, it remains to be seen if A-AVD may be better than ABVD for MTXCHL, and extra caution should be paid to myelosuppression during chemotherapy when A-AVD is used.

\section{Conflicts of Interest}

The Authors declare that they have no conflicts of interest in regard to this study.

\section{Authors' Contributions}

Kota Yoshifuji: data collection, analysis and interpretation of results, statistical analyses, construction of a figure, editing and writing of the original article; Yoshihiro Umezawa: data collection and patient management; Ayako Ichikawa: data collection and interpretation of results, statistical analyses; Ken Watanabe: data collection and patient management; Osamu Miura: supervision of the project, critical revision of the article; Masahide Yamamoto: study design, data collection analysis and interpretation of results, statistical analyses, writing of article. All the Authors read and approved the final article.

\section{References}

1 Gaulard P, Swerdlow S, Harris N, Sundstrom C and Jaffe E: Other iatrogenic immunodeficiency-associated lymphoproliferative disorders. In: Swerdlow SH, Campo E, Harris NL, Jaffe ES, Pileri SA, Stein H, Thiele J, Arber DA, Hasserjian RP, Le Beau MM, Orazi A and Siebert R: World Health Organization Classification of Tumors of Haematopoietic and Lymphoid Tissues. Revised Fourth Edition. Lyon: IARC: p. 462-464, 2017.

2 Smolen JS, Landewé R, Bijlsma J, Burmester G, Chatzidionysiou K, Dougados M, Nam J, Ramiro S, Voshaar M, van Vollenhoven R, Aletaha D, Aringer M, Boers M, Buckley CD, Buttgereit F, Bykerk V, Cardiel M, Combe B, Cutolo M, van Eijk-Hustings Y, Emery P, Finckh A, Gabay C, GomezReino J, Gossec L, Gottenberg JE, Hazes JMW, Huizinga T, Jani M, Karateev D, Kouloumas M, Kvien T, Li Z, Mariette X, McInnes I, Mysler E, Nash P, Pavelka K, Poór G, Richez C, van Riel P, Rubbert-Roth A, Saag K, da Silva J, Stamm T, Takeuchi T, Westhovens R, de Wit M and van der Heijde D: EULAR recommendations for the management of rheumatoid arthritis with synthetic and biological disease-modifying antirheumatic drugs: 2016 update. Ann Rhum Dis 76: 960-977, 2017. PMID: 28264816. DOI: 10.1136/annrheumdis-2016-210715 
3 Ellman $\mathrm{MH}$, Hurwitz $\mathrm{H}$, Thomas $\mathrm{C}$ and Kozloff M: Lymphoma developing in a patient with rheumatoid arthritis taking low dose weekly methotrexate. J Rheumatol 18: 1741-1743, 1991. PMID: 1787499.

4 Gion Y, Iwaki N, Takata K, Takeuchi M, Nishida K, Orita Y, Tachibana T, Yoshino T and Sato Y: Clinicopathological analysis of methotrexate-associated lymphoproliferative disorders: Comparison of diffuse large B-cell lymphoma and classical Hodgkin lymphoma types. Cancer Sci 108: 1271-1280, 2017. PMID: 28380678. DOI: $10.1111 /$ cas.13249

5 Niitsu N, Okamoto $M$, Nakamine $H$ and Hirano $M$ : Clinicopathologic correlations of diffuse large B-cell lymphoma in rheumatoid arthritis patients treated with methotrexate. Cancer Sci 101: 1309-1313, 2010. PMID: 20210795. DOI: 10.1111/ j.1349-7006.2010.01517.x

6 Yamada K, Oshiro Y, Okamura S, Fujisaki T, Kondo S, Nakayama Y, Suematsu E, Tamura K and Takeshita M: Clinicopathological characteristics and rituximab addition to cytotoxic therapies in patients with rheumatoid arthritis and methotrexate-associated large B lymphoproliferative disorders. Histopathology 67: 70-80, 2015. PMID: 25429725. DOI: 10.1111/his. 12627

7 Loo EY, Medeiros LJ, Aladily TN, Hoehn D, Kanagal-Shamanna R, Young KH, Lin P, Bueso-Ramos CE, Manning JT Jr., Patel K, Thomazy V, Brynes RK, Goswami M, Fayad LE and Miranda RN: Classical Hodgkin lymphoma arising in the setting of iatrogenic immunodeficiency: a clinicopathologic study of 10 cases. Am J Surg Pathol 37: 1290-1297, 2013. PMID: 23774171. DOI: $10.1097 /$ PAS.0b013e31828e6564

8 Mariette X, Cazals-Hatem D, Warszawki J, Liote F, Balandraud $\mathrm{N}$ and Sibilia J: Lymphomas in rheumatoid arthritis patients treated with methotrexate: a 3-year prospective study in France. Blood 99: 3909-3915, 2002. PMID: 12010788.

9 Cheson BD, Fisher RI, Barrington SF, Cavalli F, Schwartz LH, Zucca E and Lister TA: Recommendations for initial evaluation, staging, and response assessment of hodgkin and non-hodgkin lymphoma: The lugano classification. J Clin Oncol 32(27): 3059-3068, 2014. PMID: 4979083. DOI: 10.1200/jco.2013. 54.8800

10 Kanda Y: Investigation of the freely available easy-to-use software 'EZR' for medical statistics. Bone Marrow Transplant 48: 452-458, 2013. PMID: 23208313. DOI: 10.1038/bmt. 2012.244

11 Strati P, Fanale MA, Oki Y, Turturro F, Fayad LE, Bartlett NL, Gladstone DE, Kasamon YL, Portlock CS, Wilson WH, Goy A, Younes A and Lee HJ: Rituximab with ABVD vs ABVD for advanced stage high-risk classical Hodgkin lymphoma: a randomized phase II study. Haematologica, 2018. PMID: 30190343. DOI: 10.3324/haematol.2018.199844

12 Younes A, Oki Y, McLaughlin P, Copeland AR, Goy A, Pro B, Feng L, Yuan Y, Chuang HH, Macapinlac HA, Hagemeister F, Romaguera J, Samaniego F, Fanale MA, Dabaja BS, Rodriguez MA, Dang N, Kwak LW, Neelapu SS and Fayad LE: Phase 2 study of rituximab plus ABVD in patients with newly diagnosed classical Hodgkin lymphoma. Blood 119: 4123-4128, 2012. PMID: 22371887. DOI: 10.1182/blood-2012-01-405456
13 Voltin CA, Goergen H, Baues C, Fuchs M, Mettler J, Kreissl S, Oertl J, Klaeser B, Moccia A, Drzezga A, Engert A, Borchmann P, Dietlein $M$ and Kobe C: Value of bone marrow biopsy in Hodgkin lymphoma patients staged by FDG PET: results from the German Hodgkin Study Group trials HD16, HD17, and HD18. Ann Oncol 29: 1926-1931, 2018. PMID: 30010775. DOI: 10.1093/annonc/mdy250

14 Tokuhira M, Saito S, Okuyama A, Suzuki K, Higashi M, Momose S, Shimizu T, Mori T, Anan-Nemoto T, Amano K, Okamoto S, Takeuchi T, Tamaru JI and Kizaki M: Clinicopathologic investigation of methotrexate-induced lymphoproliferative disorders, with a focus on regression. Leuk Lymphoma 59: 11431152, 2017. PMID: 28877615. DOI: 10.1080/10428194. 2017.1369073

15 Saito S, Kaneko Y, Yamaoka K, Tokuhira M and Takeuchi T: Distinct patterns of lymphocyte count transition in lymphoproliferative disorder in patients with rheumatoid arthritis treated with methotrexate. Rheumatology (Oxford) 56: 940-946, 2017. PMID: 28165538. DOI: 10.1093/rheumatology/kex002

16 Inui Y, Matsuoka H, Yakushijin K, Okamura A, Shimada T, Yano $\mathrm{S}$, Takeuchi M, Ito M, Murayama T, Yamamoto K, Itoh T, Aiba $\mathrm{K}$ and Minami H: Methotrexate-associated lymphoproliferative disorders: management by watchful waiting and observation of early lymphocyte recovery after methotrexate withdrawal. Leuk Lymphoma 56: 3045-3051, 2015. PMID: 25721751. DOI: $10.3109 / 10428194.2015 .1022769$

17 Ichikawa A, Arakawa F, Kiyasu J, Sato K, Miyoshi H, Niino D, Kimura Y, Takeuchi M, Yoshida M, Ishibashi Y, Nakashima S, Sugita Y, Miura O and Ohshima K: Methotrexate/iatrogenic lymphoproliferative disorders in rheumatoid arthritis: histology, Epstein-Barr virus, and clonality are important predictors of disease progression and regression. Eur J Haematol 91: 20-28, 2013. PMID: 23560463. DOI: 10.1111/ejh.12116

18 Jiang Y, Chen Y, Huang R and Chen G: Comparison of the efficiency of ABVD versus BEACOPP for Hodgkin lymphoma treatment: A meta-analysis. Int J Hematol 104: 413-419, 2016. PMID: 27531149. DOI: 10.1007/s12185-016-2080-5

19 Connors JM, Jurczak W, Straus DJ, Ansell SM, Kim WS, Gallamini A, Younes A, Alekseev S, Illés Á, Picardi M, LechMaranda E, Oki Y, Feldman T, Smolewski P, Savage KJ, Bartlett NL, Walewski J, Chen R, Ramchandren R, Zinzani PL, Cunningham D, Rosta A, Josephson NC, Song E, Sachs J, Liu R, Jolin HA, Huebner D, Radford J and ECHELON-1 Study Group: Brentuximab vedotin with chemotherapy for stage III or IV Hodgkin's lymphoma. N Engl J Med 378: 331-344, 2018. PMID: 29224502. DOI: 10.1056/NEJMoa1708984

20 Nakazato T, Takanashi S, Hirano M, Ito C, Fujita Y, Osada Y, Aisa $\mathrm{Y}$ and Mori T: Brentuximab vedotin is effective for rheumatoid arthritis in a patient with relapsed methotrexateassociated Hodgkin lymphoma. Ann Hematol 97: 1489-1491, 2018. PMID: 29455236. DOI: 10.1007/s00277-018-3279-8

Received June 20, 2019

Revised July 8, 2019

Accepted July 12, 2019 